\title{
Intentionality and Minimal Rationality in the Logic of Action
}

\author{
Daniel Vanderveken
}

\begin{abstract}
Philosophers have overall studied intentional actions that agents attempt to perform in the world. However the pioneers of the logic of action, Belnap and Perloff, and their followers have tended to neglect the intentionality proper to human action. My primary goal is to formulate here a more general logic of action where intentional actions are primary as in contemporary philosophy of mind. In my view, any action that an agent performs involuntarily could in principle be intentional. Moreover any involuntary action of an agent is an effect of intentional actions of that agent. However, not all unintended effects of intentional actions are the contents of unintentional actions, but only those that are historically contingent and that the agent could have attempted to perform. So many events which happen to us in our life are not really actions. My logic of action contains a theory of attempt, success and action generation. Human agents are or at least feel free to act. Moreover their actions are not determined. As Belnap pointed out, we need branching time and historic modalities in the logic of action in order to account for indeterminism and the freedom of action. Propositions with the same truth conditions are identified in standard logic. However they are not the contents of the same attitudes of human agents. I will exploit the resources of a non classical predicative propositional logic which analyzes adequately the contents of attitudes. In order to explicate the nature of intentional actions one must deal with the beliefs, desires and intentions of agents. According to the current logical analysis of propositional attitudes based on Hintikka's epistemic logic, human agents are either perfectly rational or completely irrational. I will criticize Hintikka's approach and present a general logic of all cognitive and volitive propositional attitudes that accounts for the imperfect but minimal rationality of human agents. I will consider subjective as well as objective possibilities and explicate formally possession and satisfaction conditions of propositional attitudes. Contrary to Belnap, I will take into account the intentionality of human agents and
\end{abstract}

D. Vanderveken $(\bowtie)$

Department of Philosophy, University of Quebec at Trois-Rivières, Trois-Rivières,

QC G9A 5H7, Canada

e-mail: daniel.vanderveken@gmail.com 
explicate success as well as satisfaction conditions of attempts and the various forms of action generation. This chapter is a contribution to the logic of practical reason. I will formulate at the end many fundamental laws of rationality in thought and action.

I will only consider here individual actions and attitudes of single agents at one moment. Examples of such individual actions are intended body movements like voluntarily raising one's arm, some effects of these movements like touching something and saluting someone, mental actions like judgements and elementary illocutionary acts such as assertions and requests. Whoever performs an action at moment has individual beliefs, desires and intentions at that very moment. Individual actions (and attitudes) of agents at a single moment are the simplest kinds of action (and attitudes) from a logical point of view. They part of other kinds of individual or collective actions (and attitudes) which last during several moments of time.

In order to contribute to the foundations of the logic of action I will attempt to answer general philosophical questions: What is the logical form of proper intentional actions? Which attitudes do they contain? In my view, attempts are constitutive of intentional actions. Attempted actions have success conditions: either agents succeed or fail in performing them? How can we define success and failure? We need an account of agents' reasons in our logic of action and attitudes. Indeed agents have theoretical reasons for believing propositions and they make their attempts for practical reasons. Their intentional actions can both create reasons and be subject to demands for reasons i.e. for justifications. Moreover voluntary actions are related by the relation of being means to achieve ends (Aristotle). Agents make their attempts in order to perform other actions. How can we account for their objectives? Our intentional actions have involuntary effects in the world. In walking intentionally on the snow an agent might unintentionally slip and fall. What are the logical relations that exist between our intentional and unintentional actions? Some types of action strongly commit the agent to performing other types of action. Whoever shouts produces sounds. Any instance of an action of the first type contains an action of the second type. Moreover certain action tokens generate others in certain circumstances. Whoever expresses an attitude that he does not have, is lying. But he could be sincere at another moment. What are the basic laws governing agentive commitment and action generation? In particular, how can agents perform certain actions by way of performing others? Are all actions performed by an agent at a moment generated by a single basic intentional action of that agent at that moment? If yes, what is the nature of basic actions?

As Brentano (1993) pointed out, agents of propositional attitudes and intentional actions have intentionality: they are directed at objects and facts of the world that they represent. From a logical point of view, propositional attitudes have logically related conditions of possession and of satisfaction. Whoever possesses a propositional attitude is in a certain mental state: he or she represents what has to happen in the world in order that his or her attitude is satisfied. Beliefs are satisfied whenever they are true, desires whenever they are realized and intentions whenever they are executed. So agents having beliefs represent how things are in the world according to them. Agents having desires represent how they would prefer things to be in the world and agents having intentions represent how they should act in order to execute 
their intentions. Propositional attitudes consist of a psychological mode $M$ with a propositional content $P$. They are the simplest kinds of individual attitudes directed at facts. My first objective here is to explicate adequately possession and satisfaction conditions of all propositional attitudes. My second objective is to explicate the nature of intentional actions and the different kinds of action generation whether voluntary or not. According to standard epistemic logic human agents are either perfectly rational or totally irrational. I will advocate an intermediate position compatible with contemporary philosophy of mind according to which human agents are not perfectly but minimally rational. In my logical approach, one can formulate adequate laws of psychological commitment and avoid current epistemic and volitive paradoxes. In order to account for minimal rationality ${ }^{1} \mathrm{I}$ will exploit the resources of a non classical propositional predicative logic that distinguishes propositions with the same truth conditions that do not have the same cognitive or volitive value.

The structure of this chapter is the following. I will explain in the first section my predicative analysis of propositional contents. Next I will explicate components of psychological modes and define possession and satisfaction conditions of propositional attitudes. I will explain in the third section the principles ${ }^{2}$ of my logic of action where intentional actions are primary as in contemporary philosophy. ${ }^{3}$ Because intentional actions are actions that agents attempt to perform in the world, the basic individual actions of each agent are in my logic his or her primary attempts (usually attempts of body movement). My ideographical object-language has richer expressive capacities than that of Belnap. It expresses in addition to modalities, time and individual actions of agents, their attempts and their cognitive and volitive propositional attitudes. I will give a formal account of intentionality and explicate the nature of attempts and forms of action generation in the fourth section. ${ }^{4}$ In the last section I will enumerate a few valid laws of my logic after having criticized Searle's skepticism against the logic of practical reason. I will also explain why the logic of action is so important for the purposes of illocutionary logic.

\section{Analysis of Propositional Contents of Attitudes}

Propositions with the same truth conditions are not the contents of the same attitudes and intentional actions. One can believe and assert that Rome is a capital without believing and asserting that it is a capital and not an erythrocyte. Moreover human agents do not know a priori by virtue of competence the necessary truth of many propositions. We have to learn a lot of essential properties of objects. By essential property of an object I mean here a property that it really possesses in any possible

\footnotetext{
${ }^{1}$ The notion of minimal rationality was first discussed by Cherniak (1986).

2 These principles were first stated in my paper "Attitudes, tentatives et actions" (Vanderveken 2008a).

${ }^{3}$ See Bratman (1987), Davidson (1980), Goldman (1970), Searle (1982).

${ }^{4}$ I define a model-theoretical semantics for my object-language in my next book Truth, Thought and Action.
} 
circumstance. Each human agent has the essential property to have certain parents. But some do not know their parents. Others are wrong about their identity; in that case they have necessary false beliefs. However when agents are inconsistent, they remain paraconsistent: as the Greek philosophers pointed out, they never believe nor desire everything.

According to standard logic of attitudes (Hintikka 1971), relations of psychological compatibility with the truth of beliefs and the realization of desires are modal relations of accessibility between agents and moments, on one hand, and possible circumstances, on the other hand. Possible circumstances are compatible with the truth of agents' beliefs at each moment of time. To each agent $a$ and moment $m$ there corresponds in each model a unique set $\operatorname{Belief}(a, m)$ of possible circumstances that are compatible with the truth of all beliefs of that agent at that moment. On Hintikka's view, an agent believes a proposition at a moment when that proposition is true in all possible circumstances that are compatible with what that agent then believes. Given such a formal approach, human agents are logically omniscient. They believe all necessarily true propositions and their beliefs are closed under logical implication. Moreover, human agents are either perfectly rational or totally irrational. They are perfectly rational when at least one possible circumstance is compatible with what they believe. Otherwise, they are totally irrational. Whoever believes a necessary falsehood believes all propositions according to the standard approach. But this conclusion is clearly false.

One could introduce in logic so-called impossible circumstances where necessarily false propositions would be true. But this move is very ad hoc and neither necessary nor sufficient. In my approach, all circumstances remain possible. So objects keep their essential properties (each of us keeps his real parents) and necessarily false propositions remain false in all circumstances. In order to account for human inconsistency, we have to consider subjective in addition to objective possibilities. Many subjective possibilities are not objective. So we need a non classical propositional logic. My logic is predicative in the general sense that it takes into account acts of predication that agents make in expressing and understanding propositions. ${ }^{5}$

In my view, each proposition has a finite structure of constituents. It predicates attributes (properties or relations) of objects subsumed under concepts. We understand a proposition when we understand which attributes objects of reference must possess in a possible circumstance in order that this proposition be true in that circumstance. As Frege (1977) pointed out, we always refer to objects by subsuming them under senses. We cannot directly have in mind individual objects like material bodies and persons. We rather have in mind concepts of individuals and we indirectly refer to them and predicate attributes of them through these concepts. So our attitudes are directed towards individuals under a concept (called an individual concept) rather than towards pure individuals. By recognizing the indispensable role of concepts in reference and predication, predicative logic accounts for attitudes directed towards

\footnotetext{
${ }^{5}$ See my papers "Propositional Identity, Truth According to Predication and Strong Implication" (Vanderveken 2005a) and "Aspects cognitifs en logique intensionnelle et théorie de la vérité" (Vanderveken 2009a).
} 
inexistent and even impossible objects. It also explains why attitudes and intentional actions directed towards an individual under a concept are often not directed towards the same individual under other concepts. Jocasta, the queen of Thebes, is Oedipus' mother. In marrying Jocasta, Oedipus has then married his own mother. However he believed at the time of his wedding that he had another mother. So he did not then intend to marry his mother.

The logic of attitudes needs more than an analysis of the structure of constituents of propositions; it requires a better explication of their truth conditions. Because we ignore real denotations of most attributes and concepts in many circumstances, we understand most propositions without knowing in which possible circumstances they are true. One can refer to a friend's wife without knowing who she is. However we can always in principle think of persons who could be his wife. In my view most possible uses and interpretations of a natural language, let us say for short, most models for that language, consider a lot of possible denotation assignments to attributes and concepts in addition to the standard real denotation assignment of classical logic which associates with each propositional constituent its actual denotation in every possible circumstance. All possible denotation assignments to attributes and concepts of each model are functions of the same type; they associate with each individual concept a unique individual or no individual at all and with each attribute of degree $n$ a sequence of $\mathrm{n}$ individual concepts in every possible circumstance. According to the real denotation assignment of each model, my friend's wife is the woman with whom he is really married according to that model when there is such a person. According to other possible denotation assignments, his wife is another person or even he is not married. In spite of their differences, all possible denotation assignments respect by definition real meaning postulates that speakers have internalized in learning their language. According to any, a wife is a married woman. We ignore the real denotation of most concepts and attributes in many circumstances. We can only think of denotations that they could have. When we express concepts and attributes only some possible denotation assignments to them are then compatible with the truth of our beliefs. Suppose that according to you my friend's wife is young. In that case, possible denotation assignments according to which she is old are then incompatible with your beliefs. Possible denotation assignments rather than possible circumstances are compatible with the beliefs of agents. So my logic accounts for subjective possibilities.

In my approach, the truth definition is relative to both possible circumstances and denotation assignments. An elementary proposition predicating an extensional property of an individual object under a concept is true in a circumstance according to a denotation assignment in a model when according to that assignment the objec which falls under that concept has that property in that circumstance. Otherwise, it is false in that circumstance according to that assignment. In understanding propositions we in general do not know whether they are true or false. We just know that their truth in a circumstance is compatible with certain possible denotation assignments to their concepts and attributes, and incompatible with all others. Most propositions have then a lot of possible truth conditions. Of course, any proposition that is true in a circumstance according to a model has to be true in that circumstance according to the real denotation assignment of that model. So among all possible truth conditions 
of a proposition, its real Carnapian truth conditions correspond to the set of possible circumstances where it is true according to the real denotation assignment.

In my view, propositions are identical when they make the same predications and they are true in the same circumstances according to the same possible denotation assignments. Such a finer criterion of propositional identity explains why many strictly equivalent propositions have a different cognitive or volitive value. Propositions whose expression requires different predications have a different structure of constituents. So are necessarily equivalent propositions that Rome is a capital and that Rome is a capital and not an erythrocyte. One can express one without expressing the other. My identity criterion also distinguishes propositions that we do not understand to be true in the same circumstances: these are not true according to the same denotation assignments to their constituents. Few necessarily true propositions are obvious (or pure) tautologies that we know a priori. In order to be necessarily true a proposition has to be true in every possible circumstance according to the real denotation assignment. In order to be obviously tautological, a proposition has moreover to be true in every circumstance according to every possible denotation assignment to its constituent senses. ${ }^{6}$ Unlike the proposition that Oedipus' mother is a woman, the necessarily true proposition that she is Jocasta is not an obvious tautology. It is false according to possible denotation assignments. We now can explicate subjective and objective possibilities. A proposition is subjectively possible when it is true in a possible circumstance according to a possible denotation assignment. In order to be objectively possible it has to be true in a circumstance according to the real denotation assignment. Few subjective possibilities are objective.

The logic of action requires a ramified conception of time compatible with indeterminism. Attitudes and actions of human agents are not determined. When they do or think something, they could have done or thought something else. In branching time, a moment is a complete possible state of the actual world at a certain instant and the temporal relation of anteriority between moments is partial rather than linear. There is a single causal route to the past. However, there are multiple future routes. Consequently, the set of moments of time is a tree-like frame of the following form:

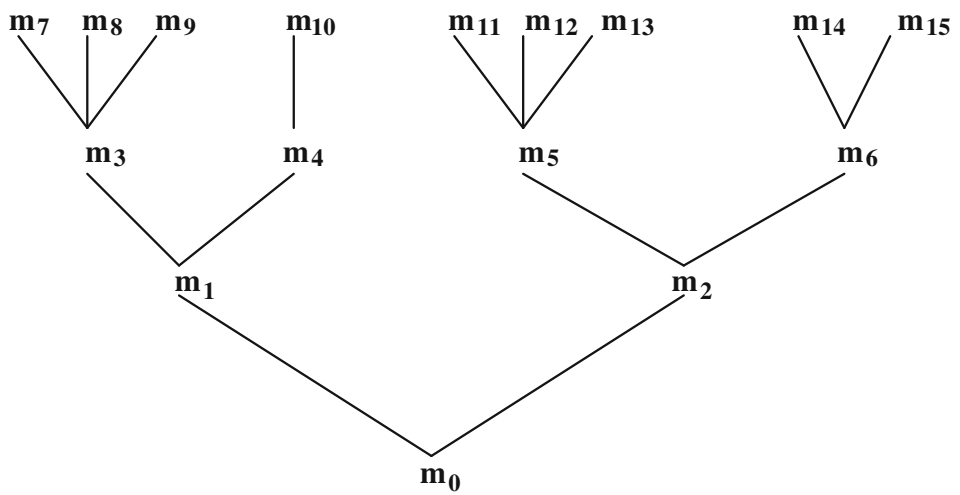

${ }^{6}$ Obvious tautologies are called pure tautologies in most of my previous papers. 
A maximal chain $h$ of moments of time is called a history. It represents a possible course of history of our world. Some histories have a first and a last moment. According to these histories the world has a beginning and an end. As Belnap et al. (2001) pointed out, each possible circumstance is a pair of a moment $m$ and of a history $h$ to which that moment belongs. Thanks to histories temporal logic can analyze important modal notions like settled truth and historic necessity. Certain propositions are true at a moment according to all histories. Their truth is then settled at that moment no matter how the world continues. So are past propositions and propositions attributing propositional attitudes to agents. Whoever desires something at a moment desires that thing at that moment no matter what happens later. Contrary to the past, the future is open. The world can continue in various ways after indeterminist moments. Thus the truth of future propositions is not settled at such moments. It depends on which historical continuation of that moment is under consideration. When there are different possible historic continuations of a moment, its actual future continuation is not then determined. However, as Occam ${ }^{7}$ pointed out, if the world continues after a moment, it will continue in a unique way. The actual historic continuation of each non final moment will be unique even if it is still undetermined at that very moment. Indeterminism cannot prevent that uniqueness.

Human agents who persist in an indeterminist world, have expectations and make plans. According to phenomenology and philosophy of mind, human agents who are directed by virtue of their intentionality towards things and facts of the world, are intrinsically oriented at each moment of their active life towards the real continuation of the world. We all ignore how the world will continue but we are intrinsically oriented at each moment towards the real continuation of that moment. So we always distinguish conceptually that real continuation from other possible continuations whenever we act or think in the world. Whoever attempts at a moment to achieve a future objective, intends to achieve that objective in the real continuation of that moment. Whoever foresees or wishes to have a future grandchild, foresees or wishes that grandchild in the real future. So in my approach both the moment and the historic continuation of the moment are to be considered in order to evaluate our actions and attitudes oriented towards the future. Consequently ${ }^{8}$ our elementary illocutions and propositional attitudes at each moment have or will have a certain satisfaction value even if that satisfaction value is still then undetermined when they have a future propositional content. In order to keep a present promise and execute a present intention to give things later, an agent must give later these things in the real continuation of the world. Other possible historic continuations do not matter. ${ }^{9}$

According to my temporal logic every moment $m$ has then a proper history $h_{m}$ in each model. Whenever a moment $m$ is the final moment of a history $h$, that history $h$ is its proper history $h_{m}$. All moments that belong to the proper history of an indeterminist moment have of course the same proper history in each

\footnotetext{
${ }^{7}$ See Prior (1967).

${ }^{8}$ See my paper "Towards a Formal Pragmatics of Discourse" (Vanderveken 2013).

${ }^{9}$ Belnap N., M. Perloff and Ming Xu who reject the idea that each moment of utterance has a proper history have to strongly complicate the theory of satisfaction. See Belnap et al. $(2001,151)$.
} 
model. A proposition is true at a moment $m$ according to a denotation assignment in a model when it is true at moment $m$ in the history $h_{m}$ of that moment according to that assignment.

Two moments of time $m$ and $m^{\prime}$ are coinstantaneous when they belong to the same instant. Coinstantaneous moments are on the same horizontal line in each treelike frame. One can analyze historic necessity by quantifying over coinstantaneous moments. The proposition that $P$ is then necessary (in symbols $\square P$ ) is true at a moment according to a model when $P$ is true at all coinstantaneous moments according to all histories in that model. The notion of historic necessity is stronger than that of settled truth. The represented fact is then not only established but inevitable. According to traditional philosophy there are no inevitable actions and intentions. Moreover the possible causes and effects so to speak of actions of any agent at a moment are limited to those which are possible outcomes of the way the world has been up to that moment. As Belnap and Perloff (1992) pointed out, in order to explicate historical relevance we must consider coinstantaneous moments having the same past. Such moments are called alternative moments. Thus $m_{1}$ and $m_{2}$ are alternative moments in the last figure. Logical or universal necessity is stronger than historic necessity. The proposition that $P$ is universally necessary (in symbols: $\square$ ) is true in a circumstance according to a model when $P$ is true in all possible circumstances in that model. In that case the fact represented is always inevitable. A proposition $P$ is obviously tautological according to a model when it is true in every possible circumstance according to any possible denotation assignment. The notion of obvious tautologyhood is the strongest modal notion. The represented fact is then analytically inevitable subjectively as well as objectively.

\section{My New Approach in the Logic of Propositional Attitudes ${ }^{10}$}

As I said earlier, propositional attitudes of human agents are about objects that they represent under concepts. Each agent has consciously or potentially ${ }^{11}$ in mind a certain set of attributes and concepts at each moment. That set of propositional constituents is of course empty when the agent does not exist. In my view, no agent can have a propositional attitude without having in mind all attributes and concepts of its content. Otherwise, he or she would be unable to determine under which conditions that attitude is satisfied. In order to desire to be bishop one must understand characteristic features determined by meaning of the property of being bishop.

Secondly, possible denotation assignments to propositional constituents rather than possible circumstances are compatible with the satisfaction of agents' attitudes.

\footnotetext{
10 See my three papers "A General Logic of Propositional Attitudes" (Vanderveken 2008b), "Beliefs, Desires and Minimal Rationality" (Vanderveken 2009b), and "On the Imperfect but Minimal Rationality of Human Agents" (Vanderveken 2012).

11 We have unconsciously in mind at each conscious moment of our existence a lot of concepts and attributes that we could in principle express at that moment given our language.
} 
So there corresponds to each agent $a$ and moment $m$ in each model a unique set Belief $(a, m)$ of possible denotation assignments to attributes and concepts that are compatible with the truth of beliefs of that agent at that moment. When the agent $a$ has no attribute in mind at the moment $m$, Belief $(a, m)$ is the entire set Val of all possible denotation assignments to senses. In that case, that agent has then no attitudes. Otherwise, $\operatorname{Belief}(a, m)$ is always a non empty proper subset of Val. For whoever has in mind senses respects meaning postulates governing them in his possible use and interpretation of language. So there always are possible denotation assignments to these senses compatible with what that agent then believes. In my view, an agent $a$ believes a proposition at a moment $m$ when he or she has then in mind all its concepts and attributes and that proposition is true at that moment according to all possible denotation assignments of Belief $(a, m)$ compatible with the truth of his or her beliefs at that moment. Our present beliefs directed at the future (previsions, expectations) will become true if things will be as we now believe in the actual future continuation of the present moment.

Similarly, to each agent $a$ and moment $m$ there corresponds in each model a unique non empty set $\operatorname{Desire}(a, m)$ of possible denotation assignments to attributes and concepts that are compatible with the realization of all desires of that agent at that moment. There is however an important difference between desire and belief. Agents can believe, but they cannot desire, that objects have properties or entertain relations without believing that they could be otherwise. For any desire contains a preference. Whoever desires something distinguishes two different ways in which represented objects could be in the actual world. In the preferred ways, objects are in the world as the agent desires, in the other ways, they are not. The agent's desire is realized in the first case, it is unrealized in the second case. Thus in order that an agent $a$ desires the fact represented by a proposition $P$ at a moment $m$, it is not enough that he or she has then in mind all attributes and concepts of $P$ and that the proposition $P$ is true at that moment according to all denotation assignments of Desire $(a, m)$ compatible with the realization of his or her desire at that moment. That proposition must moreover be false in at least one circumstance according to that agent. Otherwise that agent would not then prefer the existence of the represented fact.

My explication of belief and desire is compatible with philosophy of mind. It accounts for conscious and unconscious attitudes. Whoever has a conscious belief or desire has consciously in mind all attributes and concepts of its propositional content. Whoever has an unconscious belief or desire has unconsciously in mind some of its attributes and concepts. He or she could then express these senses thanks to his or her language. My approach also accounts for the fact that human agents are neither logically omniscient nor perfectly rational. We do not have in mind all expressible concepts and attributes. ${ }^{12}$ So we ignore tautological as well as necessary truths. Our knowledge is limited: we ignore how objects are in a lot of circumstances espe-

\footnotetext{
12 We ignore the meaning of certain words. Moreover the languages that we speak have limited expressive capacities. We regularly enrich our languages in order to express new concepts and attributes that we discover.
} 
cially in future circumstances. Many assignments associating different denotations to attributes in these circumstances are then compatible with our beliefs. We have moreover false beliefs and unsatisfied desires. So the real denotation assignment is often incompatible with the satisfaction of our beliefs and desires. Possible denotation assignments compatible with our beliefs and desires can even violate essential properties of objects. In that case we have necessarily false beliefs and insatisfiable desires. My analysis explains why we are sometimes inconsistent.

Predicative logic also explicates why propositions true in the same circumstances can have a different cognitive or volitive value. Some have different structures of constituents. So are logically equivalent propositions that mothers are women and that mothers are not ordinals. Their expression requires different acts of predication. Others are not true according to the same possible denotation assignments. So are necessarily true propositions that whales are whales and that whales are mammals. We do not understand them as being true in the same conditions. Thus we can assert or believe necessary truths without asserting or believing others. Among all necessary truths, few are obvious tautologies like the proposition that whales are whales. We believed in the past that whales were fishes.

However in my approach, human agents always remain minimally rational: they cannot be totally irrational. First of all, agents cannot believe or desire everything since in every model some possible denotation assignments are compatible with the satisfaction of their beliefs and desires. Moreover, whoever possesses certain beliefs and desires is eo ipso committed to possessing others. Indeed all possible denotation assignments compatible with our beliefs and desires respect meaning postulates. Human agents are therefore minimally logically omniscient: we cannot have in mind an obviously tautological proposition without knowing for certain that it is necessarily true. Represented objects could not be otherwise according to us. Similarly, obvious contradictions (negations of obvious tautologies) are false in every possible circumstance according to any agent. We can neither believe nor desire obvious contradictions. Some hope that arithmetic is complete (a necessarily false proposition if Gödel's proof is right). But agents could never believe or desire both the completeness and the incompleteness of arithmetic (an obvious contradiction). Moreover we cannot desire the existence of facts represented by obvious tautologies. In order to desire facts we must believe that these facts could not occur. One can desire to drink; one can also desire not to drink. But no one could desire to drink or not drink.

\subsection{Analysis of Psychological Modes and Possession Conditions of Attitudes}

Descartes in his treatise on Les passions de l'âme (Descartes 1953) analyzed a large number of propositional attitudes. Contemporary logic and analytic philosophy only consider a few paradigmatic attitudes such as belief, knowledge, desire 
and intention. Could we use Cartesian analysis to develop a larger theory of all propositional attitudes? Searle in Chap. 1 of Intentionality criticized Descartes who tends to reduce all such attitudes to beliefs and desires. Indeed many different kinds of attitudes e.g. fear, regret and sadness reduce to the same sums of beliefs and desires. Moreover, our intentions are much more than a desire to do an action with a belief that we are able to do it. Clearly all cognitive attitudes (e.g. conviction, faith, confidence, knowledge, certainty, presumption, pride, arrogance, surprise, amazement, stupefaction, prevision, anticipation and expectation) are beliefs and all volitive attitudes (e.g. wish, will, intention, ambition, project, hope, aspiration, satisfaction, pleasure, enjoyment, delight, gladness, joy, elation, amusement, fear, regret, sadness, sorrow, grief, remorse and terror) are desires. But psychological modes divide into other components than the basic categories of cognition and volition. Let me now present these new components.

Many complex psychological modes have a proper way of believing or desiring, proper conditions on their propositional content or proper preparatory conditions. First of all, we feel our beliefs and desires in a lot of ways. Many modes require a special cognitive or volitive way of believing or desiring. Thus, knowledge is a belief based on strong evidence that gives confidence and guarantees truth. Whoever has an intention feels such a strong desire that he or she is disposed to act in order to realize that desire. From a logical point of view, a cognitive or volitive way is a function $f_{\varpi}$ which restricts basic psychological categories. Like illocutionary forces, modes also have propositional content and preparatory conditions. Like predictions, previsions and anticipations are directed towards the future. Intentions are desires to carry out a present or future action. From a logical point of view, a condition on the propositional content is a function $f_{\theta}$ that associates which each agent and moment a set of propositions. The propositional content conditions of predictions and previsions associate with each agent and moment the set of propositions which are future with respect to that moment. Moreover any agent of a propositional attitude or of an elementary illocution presupposes certain propositions. Certain of these presuppositions are propositional presuppositions that depend on their propositional content. Whoever refers to the king of Belgium presupposes that there is one and only one king of Belgium. All illocutions and attitudes with the same propositional content have the same propositional presuppositions. Other presuppositions depend on the psychological mode and illocutionary force. They are determined by so called preparatory conditions. Thus promises and intentions have the preparatory condition that the agent is then able to do the action represented by their propositional content. Whoever promises and intends to do something presupposes that he or she can do it. His or her attitude and illocution would be defective if that proposition were then false. In the illocutionary case the speaker who presupposes can lie in order to mislead the hearer. In the psychological case however the agent cannot lie to him or herself. Whoever has an attitude both believes and presupposes that its preparatory conditions are fulfilled. A preparatory condition is a function $\mathrm{f}_{\Sigma}$ associating with each agent, moment and propositional content a set of propositions that the agent would presuppose and believe if he had then an attitude with that preparatory condition and propositional content. The sets of cognitive and volitive ways, of propositional 
content and of preparatory conditions are Boolean algebras. They contain a neutral element and they are closed under the operations of union and intersection.

On the basis of my analysis, one can formally distinguish different kinds of attitudes like fear, regret and sadness which apparently reduce to the same sums of beliefs and desires. Identical psychological modes have the same components. Possession conditions of propositional attitudes are entirely determined by components of their mode and their propositional content. By definition, an agent a possesses a cognitive (or volitive) attitude of the form $M(P)$ at a moment $m$ when he or she has then a belief (or desire) with the propositional content $P$, he or she feels then that belief (or desire) that $P$ in the cognitive (or volitive) way $\varpi_{M}$ proper to psychological mode $M$, the proposition $P$ then satisfies propositional content conditions $\theta_{\mathrm{M}}(a, m)$ and finally that agent then presupposes and believes all propositions $\Sigma_{\mathrm{M}}(a, m, P)$ determined by preparatory conditions of mode $M$ with respect to the content $P$. Thus an agent intends that $P$ at a moment when proposition $P$ then represents a present or future action of that agent, he or she desires so much that action that he or she is committed to carrying it out and moreover that agent then presupposes and believes to be able to carry it out. Whoever has an intention intends to act sooner or later. Sometimes the agent intends to act at the very moment of the intention. He or she has then an intention to act in the present (what Searle (1982) calls an intention in action). Sometimes the agent has a prior intention: he or she intends to act at a posterior moment. Most agents who have an intention at a moment have previously formed that intention or they form it at that very moment. They have committed themselves to doing the intended action. Whoever has the intention to act in the present forms his or her intention at the very moment of that intention. So agents of intentions in action perform the very act of forming these intentions.

An attitude strongly commits an agent to another at a moment when he or she could not then have that attitude without having the second. Thus whoever believes that it will rain tomorrow then foresees rain tomorrow. Some attitudes strongly commit the agent to another at particular moments. Whoever believes now that it will rain tomorrow foresees rain tomorrow. The day after tomorrow the same belief won't be a prevision. It will be a belief about the past. An attitude contains another when it strongly commits any agent to that other attitude at any moment. There are strong and weak psychological commitments just as there are strong and weak illocutionary commitments (see Searle and Vanderveken 1985). One must distinguish between the overt possession of an attitude and a simple psychological commitment to that attitude. Whoever believes that every man is mortal is weakly committed to believing that Nebuchadnezzar is mortal, even if he has not Nebuchadnezzar's concept in mind and if he or she does not then possess the second belief. No one could simultaneously believe the first universal proposition and the negation of the second.

Psychological modes are not a simple sequence of a basic psychological category, a cognitive or volitive way, a propositional content condition and a preparatory condition. For their components are not independent. Certain components determine others of the same or of another kind. Thus the volitive way of the mode of intention determines the propositional content condition that it represents a present or future action of the agent and the preparatory condition that that agent is then able to 
carry out that action. The two primitive modes of belief and desire are the simplest cognitive and volitive modes. They have no special cognitive or volitive way, no special propositional content or preparatory condition. Complex modes are obtained by adding to primitive modes special cognitive or volitive ways, propositional content conditions or preparatory conditions. Thus the mode of prevision $\mathrm{M}_{\text {foresee }}$ is obtained by adding to the mode of belief the propositional content condition $\theta_{\text {future }}$ that associates with each agent and moment the set of propositions that are future with respect to that moment. $\mathbf{M}_{\text {foresee }}=\left[\theta_{\text {future }}\right]$ Belief. The mode of hope is obtained from that of desire by adding the special cognitive way that the agent is then uncertain as regards the existence and the inexistence of the represented fact and the preparatory condition that that fact is then possible. The mode of satisfaction is obtained from that of desire by adding the preparatory condition that the desired fact exists. The mode of pleasure has, in addition, the volitive way that the satisfaction of the desire puts the agent in a state of pleasure and the preparatory condition that it is good for the agent. Because all operations on modes add new components, they generate stronger modes. Attitudes $M(P)$ with a complex mode $M$ contains attitudes $M^{\prime}(P)$ whose mode $M^{\prime}$ have less components. A lexical analysis of terms for attitudes based on my componential analysis explains which name stronger psychological modes. I have drawn semantic tableaux in order to show comparative strength between modes. ${ }^{13}$

Notice that contrary to truth functions, modal and temporal propositions as well as propositions attributing attitudes to agents contain more elementary propositions than their arguments. They serve indeed to predicate new modal, temporal, epistemic and volitive attributes to objects of reference. In thinking that God cannot make mistakes we predicate of Him the modal property of infallibility. In thinking that God created the world we predicate of Him the past property of having created the world. In thinking that the pope believes that God exists, we predicate of God the epistemic property of being existent according to the pope. Whoever wishes that God forgives him predicates of God the property that he would prefer His pardon.

\subsection{Analysis of Satisfaction Conditions of Propositional Attitudes}

The general notion of satisfaction condition in logic is based on that of correspondence. Agents of propositional attitudes and elementary illocutionary acts are directed towards facts of the world represented by their propositional content. Most often they establish a correspondence or fit between their ideas and things in the case of attitudes and between their words and things in the case of illocutions. Their attitudes and illocutions have for that reason satisfaction conditions. In order that the propositional attitude or elementary illocution of an agent at a moment is satisfied, there must first of all be a correspondence between that agent's ideas or words and represented things in the world in the history of that moment. The propositional

13 See the tableaux at the end of my paper "Formal Semantics for propositional attitudes" (Vanderveken 2011). 
content must represent a fact that exist at that moment or will exist in the world in its real historic continuation.

As I already said, agents live in an indeterminist world. Their future is open. At each moment where they think and act, they ignore how the world will continue. However, their attitudes and actions are always directed by virtue of their intentionality toward the real historic continuation. Whenever parents refer to their next child they refer to their next child in the real future. In order that a present attitude or illocution directed at the future be satisfied, it is not enough that things will be at a posterior moment as the agent now represents them. They must be so later in the real future. So the satisfaction of propositional attitudes and elementary illocutionary acts of an agent at a moment requires the truth at that very moment of their propositional content. The notion of satisfaction is a generalization of the notion of actual truth ${ }^{14}$ that takes into account the direction of fit of attitudes and illocutions. The relation of fit or of correspondence is symmetrical: if a proposition fits the world then the world fits that proposition. However there is more to the notion of satisfaction than to that of actual truth because one must consider the direction of fit from which the correspondence must be achieved between the mind and the world in the analysis of satisfaction of attitudes, just as one must consider the direction of fit from which the correspondence must be achieved between language and the world in the analysis of satisfaction of illocutions.

There are four possible directions of fit between ideas and things, just as there are four possible directions of fit between words and things. Just as assertive illocutions have the language-to-world direction offit, cognitive attitudes have the mind-to-world direction of fit. They are satisfied when their propositional content fits the world. In that case the agent's ideas ${ }^{15}$ must correspond to things as they are then in the world. On the contrary, volitive attitudes have the opposite world-to-mind direction of fit just as commissive and directive illocutions have the opposite world-to-language direction of fit. They are satisfied only if the world fits their propositional content. In that case represented things in the world must correspond to the agent's ideas.

Each direction of fit between mind and the world determines which side is at fault in case of dissatisfaction. In the cognitive and assertive cases, the agent is at fault in the case of dissatisfaction. So when the agent realizes that there is no correspondence between his or her ideas and represented, that agent immediately changes his or her beliefs and is ready to revise his or her assertions. This is why the truth and falsehood predicates apply so well to satisfied cognitive attitudes and assertive illocutions. A belief and an assertion at moment are satisfied when they are then true and unsatisfied when they are then false. Satisfaction and dissatisfaction amount to actual truth and actual falsehood in the case of cognitive attitudes and assertive illocutions. However, the truth predicates do not apply at all to volitive

\footnotetext{
14 We need an actuality connective for a right account of satisfaction conditions. A proposition of the form Actually $P$ is true in a circumstance $m / h$ when it is true at the moment $m$ according to its history $h_{m}$.

15 In the case of illocutions the agent's ideas are the ideas that he or she expresses by his or her words.
} 
attitudes whose direction of fit goes from things to mind just as they do not apply to commissive and directive illocutions whose direction of fit goes from things to language. For the world and not the agent is at fault in the case of dissatisfaction of volitive attitudes and commissive and directive illocutions. In that case, the agent can keep his desires and remains dissatisfied. He can repeat his previous commissive and directive illocutions. So we use other predicates of satisfaction. Satisfied wishes and desires are realized; satisfied hopes and aspirations are fulfilled, and satisfied intentions, projects and plans are executed. Satisfied promises and vows are kept, satisfied orders and commands are obeyed, satisfied requests are granted, etc.

Most often, agents having a volitive attitude desire the existence of the fact represented by the propositional content no matter how that fact turns to be existent in the world. So most volitive attitudes that agents have at a moment are satisfied when their content is then true, no matter for which reason. Things are then such as the agent desires them to be, no matter what is the cause of their existence. The only exceptions to this rule are volitive attitudes like will, intentions, projects, plans and ambitions whose proper volitive way requires that things fit the agent's ideas because he or she wants them in that way. Like commissive and directive illocutionary acts (orders, commands, pledges and promises), such volitive attitudes have self-referential satisfaction conditions. Their satisfaction requires more than the existence of the fact represented by their propositional content. It requires that that fact turns to be existent in order to satisfy the agent's attitude. In order to execute a prior intention and to keep a previous promise, an agent must do more than carry out later the intended and promised action in the real future; he or she must carry out that action because of that previous intention and promise. If the agent does not act for that reason, (that agent has forgotten his or her previous intention and promise or he or she does not act freely), that agent does not then execute the prior intention (or keep then the previous promise). Like illocutionary logic, the logic of attitudes can explain such a self-referential satisfaction by relying on intentional causation. The attitude and illocution of the agent are then a practical reason why the represented fact turns to be existent. ${ }^{16}$

As Searle pointed out in Intentionality, certain volitive modes like joy, gladness, pride, pleasure, regret, sadness, sorrow, and shame have like expressive illocutions the empty direction of fit. Agents who have such attitudes do not want to establish a correspondence between their ideas and represented things in the world. They just take for granted either correspondence or lack of correspondence between their ideas and things. In the case of joy, gladness, pride and pleasure, the agent believes that the desired fact exists. In the case of regret, sadness, sorrow and shame, he or she believes on the contrary that it does not exist. The first attitudes have the special preparatory condition $\Sigma_{\text {Truth }}$ that their propositional content is then true. The second attitudes which contain a desire of the inexistence of the fact represented by their propositional content have the opposite preparatory condition $\Sigma_{\text {Falsehood }}$ that their content is then false. Volitive attitudes with such special preparatory condition have the empty direction of fit because their agent could not intend to establish a

16 My logic of action has a reason connective to express intentional causation. 
correspondence. This is why they do not have satisfaction conditions. Instead of being satisfied or dissatisfied, they are just appropriate or inappropriate. They are inappropriate when their preparatory condition of actual truth or falsehood is wrong or when their proper psychological mode does not suit the fact represented by their content. No agent should be ashamed of an action that he has not made or that is exemplary and good for all.

As Candida de Sousa Melo (2002) pointed out, declaratory acts of thought have the double direction of fit between mind and things. In making verbal and mental declarations, the speaker changes represented things of the world just by way of thinking or saying that he is changing them. Whoever gives by declaration a name to a new thing acts in such a way that that thing has then that name. In such a case, an act of the mind brings about the represented fact. Because attitudes are states and not mental actions, they could not have the double direction of fit.

\section{Intentionality in the Logic of Action}

The aim of this section is to give a formal account of the intentionality of human agents and to explicate the nature of their intentional and basic individual actions. By way of performing individual actions at a moment, agents bring about facts in the world. They make then true propositions representing these facts. Whenever they act intentionally they are moreover directed towards facts that they attempt to bring about in the world. The logical constant of Belnap's logic is the connective stit ("sees to it that") which serves to express propositions according to which an agent $a$ does $P$ (in symbols $[a$ stit $P]$ ). Because attempts are constitutive of intentional actions, my logic contains a new logical constant Tries of attempt in order to express propositions of the form [a Tries $P$ ] according to which the agent $a$ tries to do $P$. Notice that propositions that attribute actions and attempts to agents predicate new agentive attributes. In thinking that a police officer is making the hostages free, we attribute to that officer the agentive property of freeing hostages. Prefixes like "en" serve to compose agentive predicates in English. To enable is to make able and to enrich is to make rich. Similarly in thinking that a person is making an attempt to be elected, we attribute to that person the agentive property of being a candidate for an election. We need an analysis of agentive attributes in the logic of action.

I will first make basic considerations about individual actions and attempts. When an agent performs the individual action of bringing about a fact at a moment, he or she performs that action at that moment no matter how the world continues. The truth (or falsehood) of propositions of the form $[$ a stit $P]$ is then well established at each moment. Agents can repeat individual actions of the same type at different successive moments in a possible course of the world. They can request and request again. Agents also perform individual actions of the same type at alternative moments. When a player is in a checkmate position at a moment in a chess game, that player is a loser at all alternative moments where he or she makes a move in that game. Moments of time are logically related by virtue of actions of agents at these moments. From 
a logical point of view, to each agent $a$ and moment $m$ there always corresponds in each model the set Action ${ }_{m}^{a}$ of coinstantaneous moments $m^{\prime}$ which are compatible with all the actions that agent $a$ performs at the moment $m$. They are all, as Chellas (1992) would say, "under the control of-or responsive to the actions of" of that agent at that moment. When an agent $a$ does not act at all at moment $m$, all moments coinstantaneous with $m$ are compatible with his or her actions at that moment. However, when he or she does $P$ at moment $m$, the proposition $P$ is true at all moments $m^{\prime} \in$ Action $_{m}^{a}$ according to any history. In my view, the relation of compatibility with actions is reflexive, symmetric and transitive. So when a moment is compatible with all actions of an agent at another moment, that agent performs exactly the same actions at these moments. Of course because of indeterminism, the same actions of that agent can have different physical effects (that are not actions) in the world at different moments which are compatible with what he or she does at that moment. Every agent persists in the world. What an agent does at a moment depends on how the world has been up to that moment. This is why the relation of compatibility with actions satisfies the so called historical relevance condition. Only alternative moments having the same past as $m$ can belong to Action $_{m}^{a}$. Moreover, as Belnap said, the world goes on. Agents act in the same world. So at least one moment $m^{\prime}$ belongs to both sets Action ${ }_{m}^{a}$ and Action $_{m}^{b}$ for any two agents $a$ and $b$.

Thanks to the new compatibility function, logic can start to analyze individual actions. The proposition that $P$ is true given what agent a does (in symbols $\Delta a P$ ) is true in a circumstance $m / h$ according to a model when proposition $P$ is true at all moments $m^{\prime} \in$ Action $_{m}^{a}$ compatible with the actions of agent $a$ at $m$ according to all histories $h^{\prime}$. Chellas (1992) tends to identify the very notion of action with the normal modal operation corresponding to $\Delta$. However each proposition of the form $\Delta a P$ is true whenever proposition $P$ is historically necessary. But no agent could bring about an inevitable fact. Inevitable facts exist no matter what we do. So as Belnap pointed out, proposition $[a$ stit $P$ ] is stronger than $\Delta a P$; it implies that $P$ could be false.

In their logic of agency, Belnap and Perloff (1992) use the logic of branching time and von Neumann's theory of games. Agents make free choices in time. The notion of acting or choosing at a moment $m$ is thought of as constraining the course of events to lie within some particular subset of the possible histories available at that moment. Belnap and Perloff first studied actions that are guaranteed by a past choice of the agent. They made a theory of the so called achievement stit. However often agents succeed in doing things that they had no prior intention to do. They spontaneously attempt to do them. Moreover sometimes they do things that they would not have wanted to do. Belnap et al. (2001) came to study later actions directed at the future that are guaranteed by a present choice of the agent. They made a theory of the deliberative stit.

My logic of agency is more general; it deals with individual actions made at the very moment of the agent's choice, no matter whether these actions are oriented towards the present or the future. Attempts require a present choice of their agent. Every intentional action contains a present intention in action, few execute a prior intention. Most successful spontaneous attempts to move parts of one's body cause the movement at the very moment of the attempt. We emit sounds when we try to 
emit them in the contexts of oral utterances. Belnap's analysis of action in terms of ramified time has the merits of taking very seriously into consideration the temporal and causative order of the world. I follow his approach under many aspects. But I want to take into account the proper intentionality of agents that Belnap ignores. For that reason, agents carry out too many actions in his logic. Suppose that a proposition strictly implies another which is not then necessary. According to his analysis, an agent cannot make the first proposition true without also making the second true, even when the second proposition represents a fact that no agent could bring about or even try to bring about at that moment. Thus whoever repeats an action sees to it that he does that action and has done it in Belnap's logic.

Let me now repeat the principles of my approach. ${ }^{17}$ In my logic, intentional actions are primary as in philosophy. Some of our actions are involuntary. But any agent who performs unintentionally an action could in principle have attempted that action, and that unintentional action is generated by his or her intentional actions. The basic actions of agents are their primary attempts that are means to make all their other attempts; they generate all their other actions whether intentional or not. Agents know and intend few effects of their basic actions. A lot of their actions are then involuntary. However, not all unintended effects of intentional actions are involuntary actions, but only those that are historically contingent and that the agent could have attempted. In moving we inevitably agitate subatomic particles. Sometimes we are mistaken and we fail. Such events which happen in our life do not constitute actions. Indeed we could not move without agitating particles and our mistakes and failures could not be intentional. ${ }^{18}$

My logic of action contains a theory of attempt and of action generation. In my analysis, attempts are actions that agents make (rather than attitudes that they have). Attempts are actions of a very special kind: personal, conscious, intentional, free and successful. Only the agent can make his or her individual attempts. No one else can make them. Thus when two agents succeed in doing the same action (e.g. to drink) they do it thanks to different personal attempts (in that case different body movements). Attempts are intrinsically intentional actions. There are no involuntary attempts. When an agent makes an attempt, he or she makes that attempt in order to do something else. Attempts are means to achieve ends. Whoever attempts to make an attempt succeeds in making that attempt, but he or she can fail to reach his or her objective. An attempt is essentially a mental act. Whoever attempts to raise the arm can fail because of an external force. But he or she has anyway mentally made that attempt in forming consciously his or her present intention to raise the arm. Among intentional actions, attempts have then particular success conditions. It is enough to try to make an attempt in order to make it eo ipso. Direct attempts by an agent to move parts of one's body are real basic actions. When an agent forms the present intention to make a direct movement, an attempt is caused by the very formation of

\footnotetext{
${ }^{17}$ See Vanderveken (2005b, 2008a).

18 Goldman (1970) notices that certain act properties like misspeaking, miscalculating, miscounting seem to preclude intentionality. Such properties are not really act properties. We "suffer" mistakes. We do not make them.
} 
that present intention, no matter whether he or she is in a standard condition or not (Goldman 1970, 65). In case the agent of an attempt fails to reach his or her objective, his or her attempt is then unsatisfied. In order to make a satisfied attempt, one must make a good attempt in a right circumstance. Whoever attempts to invite a certain person fails when he uses a wrong name or speaks to the wrong person. When agents attempt to perform illocutions, the satisfaction conditions of their attempts are in that case the so called success conditions of their attempted illocutions. Agents often have an experience of their attempt when they fail (Searle 1982). Such an experience presents or represents the satisfaction conditions of that attempt. ${ }^{19}$

My logic of action accounts for the minimal rationality of agents who are neither perfectly rational nor entirely irrational. Minimal rationality in action is related to the ways in which agents determine satisfaction conditions of their attempts. We can intend and attempt to do impossible actions. However there are impossible actions that we can neither intend nor attempt to do. My approach represents adequately satisfaction conditions of intentions and attempts. To each agent $a$ and moment $m$ there correspond two non empty sets: Intention $_{m}^{a}$ and Attempt ${ }_{m}^{a}$ in every model. Intention $_{m}^{a}$ contains all denotation assignments to senses which are compatible with the execution of all intentions of that agent at that moment; Attempt ${ }_{m}^{a}$ is the set of all pairs of denotation assignments to senses which are respectively compatible with the realisation and the satisfaction of his or her attempts at that moment. Attempts like intentions have the world-to-mind direction of fit. Only realized attempts can be satisfied. Consequently all denotation assignments to senses compatible with the satisfaction of attempts of an agent at a moment are compatible with their realisation at that very moment: $i d_{2}$ Attempt $_{m}^{a} \subseteq i d_{1}$ Attempt $_{m}^{a}$. (In my symbolism, for any Cartesian product $X \times Y$, $i d_{1}(X \times Y)=X$ and $i d_{2}(X \times Y)=Y$.) In my view, any agent of an attempt forms the present intention to make then his or her attempt. Because that attempt has an objective, he or she also forms the intention to achieve that objective at that moment or later in the real historic continuation. Formally, $i d_{2}$ Attempt $_{m}^{a} \subseteq$ Intention $_{m}^{a} \subseteq$ Desire $_{m}^{a}$. Moreover, because attempts are actions, each agent makes the same attempts at all moments compatible with his or her actions. Thus $i d_{1}$ Attempt $t_{m}^{a}=i d_{1}$ Attempt $_{m^{\prime}}^{a}$ when $m^{\prime} \in$ Action $_{m}^{a}$. And similarly for $i d_{2}$ Attempt $_{m}^{a}$. There is no action without attempt. Consequently Action $_{m}^{a}$ is the set of all coinstantaneous moments with $m$ when all possible denotation assignments to senses belong to the set $i d_{1}$ Attempt $_{m}^{a}$. Different agents can attempt to achieve the same objective (to push the car). However no agent can make the attempt of another agent. Each agent does something irreducibly personal when he or she makes an attempt. That agent forms then his or her present intention of making that attempt. No one else can form that intention. So $i d_{1}$ Attempt $_{m}^{a} \neq i d_{1}$ Attempt $_{m}^{b}$ when $a \neq b$.

In order that an agent $a$ try to make a proposition true at a moment $m$ according to a model, it is necessary but not sufficient that that proposition is true at that moment $m$ in history $h_{m}$ according to all denotation assignments of $i d_{2}$ Attempt $_{m}^{a}$. Agents never

\footnotetext{
${ }^{19}$ Direct attempts of moving one's body contain a presentation and attempts of making an illocution a representation of their satisfaction conditions. Searle (1982) does not really consider the fact that attempts are themselves actions.
} 
intend and attempt to make true propositions that are obviously tautological. They only intend and attempt to carry out present or future actions. Because attempts are intentional actions, they have the same propositional content conditions as intentions. The set of propositions representing the objectives of an agent $a$ at moment $m$ according to a model is included in the set $\theta_{\text {intention }}(a, m)$. In my approach, a proposition of the form [ $a$ Tries $P$ ] according to which an agent $a$ attempts to bring about the fact represented by $P$ is true in a circumstance $m / h$ when firstly, that agent forms the conscious intention that $P$ at that moment (and consequently at all alternative moments $m^{\prime} \in$ Action $_{m}^{a}$ compatible with his or her actions then) and secondly, the proposition $P$ is true at moment $m$ in the history $h_{m}$ according to all denotation assignments of $i d_{2}$ Attempt $_{m}^{a}$ compatible with the satisfaction of his or her attempts at that moment. ${ }^{20}$ Every attempt at a moment is then well established and his or her agent believes then to be able to reach its objective. Moreover the agent attempts to make all his or her attempts. Because agents are minimally rational they never attempt nor intend to do things that they know to be necessary or impossible. They also never attempt nor intend to do something in the past.

As one can expect, the set Goal $_{m}^{a}$ of all propositions representing objectives aimed by an agent $a$ at the moment $m$ is empty in a model when the agent $a$ is unconscious or does not act at all at that moment according to that model. Attempts are indeed conscious actions. Each agent attempts to achieve the same goals at every moment compatible with his or her actions. Goal ${ }_{m}^{a}=$ Goal $_{m^{\prime}}^{a}$ when $m^{\prime} \in$ Action $_{m}^{a}$. Any non empty set Goal $_{m}^{a}$ is moreover finite. Human agents can only make a finite number of predications and consequently they can only form finitely many intentions and make finitely many attempts. The objectives of an agent at a moment are either present or future. Whenever the agent attempts to achieve a present objective, he or she either succeeds or fails at the very moment of his or her attempt. That attempt is then either satisfied or unsatisfied. In case the agent has a future objective (he requests an answer), he or she forms a prior intention and it is not then determined whether the attempt will or not be satisfied. All depends on what will happen in the real future. No agent can succeed in achieving at a moment a future objective. Remember that future propositions are false at each final moment. The most that agents can do is to act in such a way that the future fact that they intend to bring about will sooner or later come into existence, if the world continues, no matter how. Whoever hurts mortally an adversary will provoke his or her death if the world goes on, given actual physical laws. Agents can make more or less good contributions to the achievement of their future objectives. By making a move in a chess game one can put the adversary in an inevitable losing position. In that case it is then settled that one will be the winner if the game is pursued.

At each moment of action, any agent makes a few very basic attempts whose objectives are present and entirely personal to him or her. So are our primary attempts to move directly parts of our body or to make purely mental acts of conceptual thought

\footnotetext{
${ }^{20}$ Bratman (1987) criticizes the principle that whoever attempts to do something intends to do it. But his counter-examples do not work or they concern attempts that are not momentary but last during an interval of time.
} 
like a judgement in soliloquy. Let BasicGoal ${ }_{m}^{a}$ be the set of all propositions of Goal $_{m}^{a}$ that represent the very basic attempts of the agent $a$ at a moment $m$. Two non empty sets BasicGoal ${ }_{m}^{a}$ and BasicGoals $s_{m}^{b}$ are disjoint when their agents $a$ and $b$ are different. All our attempts at a moment are related by the relation of being means to achieve our goals at that very moment. Our few basic attempts at each moment are therefore primary in a double sense. First, they are not effects of other attempts. Second, they all together cause all our other attempts because they are made for that purpose.

As philosophers pointed out, human agents act intentionally and especially they form their attitudes and they make their attempts for certain practical reasons, because they have then certain beliefs, desires, intentions and objectives and also because of simultaneous and sometimes anterior actions, illocutions and attitudes. They have cognitive attitudes and believe propositions for theoretical reasons. Their actions and attitudes are often motivated by several reasons. They keep a previous promise not only because they have put themselves under the obligation to keep it but also in order to please the hearer and get a favour. They suppose or believe that a proposition is true because of their previous experience and of background or social knowledge. However they would not make their attempts and they would not have their cognitive attitudes if they had no practical and no theoretical reasons at all. Indeed their practical and theoretical reasons are the very intentional causes of their attempts and cognitive attitudes. For each agent $a$ and moment $m$ let Reasons ${ }_{m}^{a}$ be the set of propositions representing all theoretical and practical reasons of that agent at that moment according to a model. Each agent has of course the same practical reasons to make his or her attempts at each moment compatible with his or her actions. Among the practical causes of any attempt there is the agent's conscious intention to make that attempt. There are also his or her basic attempts that cause at that moment all his or her other attempts. BasicGoal ${ }_{m}^{a} \subset$ Reasons $_{m}^{a}$.

As I said earlier, agents succeed in performing attempted actions, when they make good attempts in right circumstances. It remains to explicate fully the notion of success. As Davidson and Searle pointed out, in order that an agent succeeds in bringing about a fact, it is not enough that he or she tries and that the fact occurs. The attempted fact must be caused by his or her own attempt. Otherwise, the agent failed. Sometimes the agent's attempt is the cause why the attempted fact occurs. Often however there is causal overdetermination. This happens when several agents bring about the attempted fact, or when the agent brings about the fact because of several simultaneous attempts. In such cases the agent's attempt under consideration is just a practical reason among others why the attempted fact occurred. One cannot then assert counterfactually that if the agent had not made that particular attempt, the fact would not have occurred. Like illocutionary logic, the logic of action must consider agents' practical reasons in order to explicate intentional causation and satisfaction-conditions of attempts. Attempts like commissive and directive illocutions have the things-to-mind direction of fit. In order that an agent succeeds in achieving an objective, his or her attempt must be a practical reason of his or her success.

However the logic of action has to consider other causes than agents' practical reasons in order to explicate success. As Goldman pointed out, certain attempt tokens 
generate other action tokens in various ways. In addition to intentional causes, natural causes, conventions as well as particular facts existing in the situation in which they act, enable agents to achieve their objectives. An agent who moves the hand touches material objects that constitute an obstacle. He or she would not touch such objects in another situation where they would not be present. Whoever flips the switch succeeds in turning on the light when the electric lighting system works. The agent's attempt physically causes light because of other facts (there is electric transmission) existing in the situation where he or she acts. His or her attempt and these other facts all together physically cause the intended effect given laws of nature. As I said earlier, the logic of ramified time takes into consideration the causative and temporal order of the world. Thus all pertinent natural laws thanks to which agent acts at a moment hold by hypothesis at all coinstantaneous moments.

Agents also succeed in achieving their objectives because of established conventions. According to conventions, certain action tokens count as constituting others in certain situations. By raising the hand, one succeeds in voting for a proposition in a meeting where participants follow such a convention. Agents of course know their practical reasons as well as the conventions that they follow in making their attempts. But they do not know all relevant physical laws; they often ignore particular physical causes and facts of the situation and sometimes even established conventions which enabled them to achieve their objectives. Logic has to take into consideration such other reasons for success.

Now when an agent succeeds in achieving an objective because of certain conventions, natural causes and particular facts, these conventions are established and these causes and particular facts exist by hypothesis in what philosophers call the situation where the agent acts. These established conventions, causes and particular facts exist even at all moments compatible with the actions of that agent at that moment, no matter whether or not he or she is aware of them. At each moment $m$ where an agent $a$ acts, propositions that represent all other reasons for his or her success at that moment are then true at all alternative moments $m^{\prime} \in$ Action $_{m}^{a}$. Moreover, given preceding considerations, when the achievement of the agent's objective is due to natural causes, conventions and particular facts existing in the situation of his or her attempt, it is then historically necessary that these natural causes, conventions and facts cause the existence of attempted facts at all moments which are coinstantaneous with the moment of action of that agent.

One can express and interpret in my logic propositions according to which the agent's attempt to bring about certain facts is a practical reason for the truth of certain propositions.

In my symbolism such propositions are of the form $[\rho[\Delta a Q][$ aTries $P]])$ : they mean that $Q$ is true given what agent $a$ does because he or she tries $P$. In my approach, a proposition of the form $[\rho[\Delta a Q][$ aTries $P]]$ is true in a circumstance $m / h$ when firstly, both propositions $[\triangle a Q]$ and [aTries $P]]$ are true in that circumstance, secondly, $Q$ is not then historically necessary (it is false in at least one circumstance whose moment is coinstantaneous with $m$ ) and thirdly, for some proposition $R$ true in all circumstances $m^{\prime} / h^{\prime}$ compatible with $a$ 's actions at $m$, it is then historically necessary that both $[$ aTries $P]$ and $R$ implies $[\Delta a Q]$, that is to say when both [aTries $P$ ] 
and $R$ are true in a circumstance coinstantaneous with $m$, so is [ $\Delta a Q]$. The new proposition $R$ represents all particular facts, natural causes and established conventions existing in the situation of the agent that are other reasons why the agent brings about the fact represented by $Q$.

On the basis of preceding considerations, I define as follows success and failure. In my object-language the two formulas [a succeeds $P$ ] and [aFails $P]$ ) which mean respectively that agent $a$ succeeds and that agent a fails in doing $P$ are abbreviations.

$$
\begin{aligned}
& {[\text { a succeeds } P]==_{\operatorname{def}}([\text { aTries } P]) \wedge[\Delta a P] \wedge(\neg \square P) \wedge[\rho[\Delta a P][\text { aTries } P]] .} \\
& \text { And }[\text { aFails } P]==_{\operatorname{def}}([\text { aTries } P]) \wedge([\neg \Delta a P] \vee(\square P) \vee(\neg \rho[\Delta a P][\text { aTries } P])) .
\end{aligned}
$$

No agent can succeed or fail in doing something unless he or she makes an attempt. So we do not succeed in performing our unintentional actions. We just perform them.

How could we now explicate the general notion of an individual action (whether intentional or not)? Given the principles of my approach, I advocate the following definition: an agent $a$ acts so as to bring about $P$ at a moment when firstly, the proposition $P$ is true given what he or she then does, secondly, $P$ is then historically contingent, thirdly, the agent $a$ could then try $P$ and fourthly, he or she brings about $P$ because of a present attempt at that moment. In other words, a proposition of the form [ $a$ stit $P$ ] is true in a circumstance $m / h$ according to a model when the proposition $P$ is false in at least one coinstantaneous circumstance, but $P$ is true at all alternative moments $m^{\prime} \in$ Action $_{m}^{a}$ according to all histories, there is at least one coinstantaneous moment $m^{\prime}$ where $P \in$ Goal $_{m^{\prime}}^{a}$ and the proposition $[\rho[\Delta a P][$ aTries $Q]]$ is true in circumstance $m / h$ for at least one proposition $Q \in G^{\prime} a l_{m}^{a}$. In my conception of action, there is no action without a simultaneous attempt of the agent. What agents do at each moment has to be caused by their intentional actions at that very moment. Thus dead agents do not act anymore even if their actions can still have effects after their death. According to philosophers, certain basic intentional actions generate all our other actions. So are in my approach the sums of our basic attempts at each moment. Because they are attempts, we succeed in performing our basic actions whenever we attempt them. Using the counterfactual conditional, one can say that if an agent had not made his or her basic attempts at that moment he or she would not then have done anything. In my logic the conjunction $\left(P_{1} \& \ldots \& P_{n}\right)$ of all $P_{k} \in$ BasicGoal $_{m}^{a}$ represents the basic action of agent $a$ at moment $m$. Whenever $\mathrm{P}_{k} \in$ BasicGoal $_{m}^{a}$, there is no other $Q \in$ Goal $_{m}^{a}$ such that the attempt that $Q$ is a practical reason for $P_{k}$.

\section{Fundamental Valid Laws}

In his paper on "Desire, Deliberation and Action", Searle (2005) expressed skepticism about the logic of practical reason. Of course, because of their proper things-to-mind direction of fit, desire and other volitive modes have properties 
like indetachability and unavoidable inconsistency which complexify their formal explication. Agents of deliberations are not forced to commit themselves at the end to given actions. They can revoke their prior intentions and not attempt to execute them. When they make an attempt, they can fail. Such properties do not at all prevent the development of the logic of practical reason. My logic of attitudes and action explicates them entirely. Searle is moreover forced to admit the existence of internalized logical relations of psychological and illocutionary commitment and incompatibility because of the very principles of his philosophy of mind. According to him, any agent of an attitude and of an intentional action has in mind the satisfaction conditions of that attitude and the success conditions of that action. Consequently, agents cannot have certain attitudes without having others and they cannot make certain actions without making others and having certain attitudes.

In my approach, there is a proper logic (a recursive theory of possession and satisfaction) for volitive attitudes just as there is a proper logic (a recursive theory of success and satisfaction) for attempts and commissive and directive illocutions ${ }^{21}$ which all have the things-to-mind direction of fit. All kinds of attitudes and actions are logically related by virtue of their felicity conditions. My logic explicates formally specific properties of attitudes and illocutions with the things-to-mind direction of fit. It also revises the current logical conception of rationality in explicating why agents are imperfectly rational, why they are sometimes inconsistent and why they do not make all valid theoretical inferences. It moreover explicates why they are not logically omniscient, why they can ignore obvious tautologies as well as necessary propositions. In my logic, the set of beliefs is neither closed under tautological nor under strict implications. Indeed many propositions tautologically and strictly imply other propositions with new concepts or attributes that agents might not have in mind. Agents also ignore how propositions are related by strict implication. My logic also explicates why agents always remain minimally rational in thinking and in acting and solves psychological and illocutionary paradoxes like the paradoxes of the liar and of the sophist. They are indeed minimally consistent; they cannot believe that an obvious tautology is false. So agents know that certain facts could not occur without others.

My predicative logic explicates a new strong propositional implication that is much finer than Lewis' strict implication and important for the analysis of strong and weak psychological commitments. Formally, a proposition strongly implies another when firstly whoever expresses that proposition can express the other and secondly, it cannot be true in a circumstance according to a possible denotation assignment unless the other proposition is also true in that circumstance according to that assignment. Strong implication is finite, tautological, paraconsistent, decidable and a priori known. Whoever believes a proposition also believes any proposition that it strongly implies. He or she knows that it could not be true otherwise. Strong implication is also partially compatible with desires, intentions and attempts. Whenever a proposition strongly implies another, whoever attempts or intends to make it true also attempts

21 See the two volumes of my book Meaning and Speech Acts (Vanderveken 1990, 1991). 
or intends to make true the other in case that other proposition represents then a possible goal of that agent.

Of course, the logic of desire and intention is very different from that of belief. Agents can both intend to do something and believe that their intended action will have a certain effect without eo ipso desiring and intending to produce that effect. One can reject an offer and believe that one will irritate the agent of that offer without desiring and intending to provoke such an attitude. There is sometimes a conflict between the intentions and beliefs of an agent at a moment. Certain possible denotation assignments to senses compatible with the execution of the agent's intentions at a moment are not compatible with the truth of his or her beliefs at that moment. For unwanted effects of the intended action do not occur according to the first assignments. Agents know that some of their beliefs could be false. This can even occur when they believe that it is settled or even inevitable that their action will have a certain unwanted consequence. Bratman and Searle have given a lot of convincing examples. A prior intention to do something $P$ and a belief that it is then necessary that if $P$ then $Q$ do not commit the agent to a prior intention to do $Q$. We know that we can wrongly believe that certain facts are inevitable. We would then be happier if such facts would not occur. So Kant's principle: "Whoever intends to achieve an end thereby will the necessary means or effects that he or she knows to be part of the achievement of that end" does not apply to prior intentions.

However because agents are rational they have to minimally coordinate their cognitive and volitive states in trying to act in the world. So a restricted form of Kant's principle "Any agent who wills the end is committed to willing the necessary means" applies to attempts which are intentions in action. In case the agent of an attempt knows that in order to succeed he or she has to do something else, that agent will try to do that other thing. In other words, whoever attempts to achieve an end attempts to use means that he or she knows to be necessary. Such a restricted Kantian principle is valid in my logic of action. When $P$ and $Q \in \theta$ Present Intention $(a, m)$ and the agent $a$ knows at moment $m$ that $\square(P \Rightarrow Q)$, if $P \in$ Goal $_{m}^{a}$ then $Q \in$ Goal $_{m}^{a}$. Let me give an example. Any agent knows that in order to invite someone one has to make a request. Thus whoever tries to make an invitation eo ipso tries to make a request. His or her attempted request then constitutes his or her attempted invitation.

As Goldman pointed out, certain action tokens generate others causally, conventionally, simply and by extension. My logic of action explicates the various forms of action generation. It can also characterize how illocutions which are the primary units of meaning and communication in the use of language relate to other speech-acts (acts of utterance, propositional acts, attempts at performing illocutions, and perlocutionary acts). Attempts at performing illocutions are new fundamental speech-acts in my taxonomy. They are constitutive of meaning. Speakers attempt to publicly perform illocutions by emitting signs. It remains to explicate how and under what conditions they succeed and how successful illocutions generate others (invitations contain requests) and have perlocutionary effects (the hearer is sometimes influenced). At the basis of communication, agents attempt to move parts of their body and this generates in the sense of Goldman in various ways their speech-acts. Generation in communication is first physically causal (we orally utter sentences in producing 
sounds), next conventional (sentence-meaning serves to determine attempted illocutions). Generation is sometimes simple (speakers succeed to perform attempted illocutions when they use appropriate words in the right contexts) or by extension (they sometimes indirectly perform non-literal illocutions). In order to explicate different kinds of speech-act generation, I intend to integrate illocutionary logic within the logic of action.

Open Access This chapter is distributed under the terms of the Creative Commons Attribution Noncommercial License, which permits any noncommercial use, distribution, and reproduction in any medium, provided the original author(s) and source are credited.

\section{References}

Belnap, N., and M. Perloff. 1992. The way of the agent. Studia Logica 51(3/4): 463-484.

Belnap, N., M. Perloff, and M. Xu. 2001. Facing the future. Agents and choices in our indeterminist world. Oxford: Oxford University Press.

Bratman, M. 1987. Intentions, plans and practical reason. Cambridge, MA: Harvard University Press.

Brentano, F. 1993. Psychology from an empirical standpoint. London: Routledge and Kegan Paul.

Chellas, B.F. 1992. Time and modality in the logic of agency. Studia Logica 51(3/4): 485-518.

Cherniak, C. 1986. Minimal rationality. Cambridge, MA: M.I.T. Press.

Davidson, D. 1980. Essays on action and events. Oxford: Oxford University Press.

Descartes, R. 1953. Les passions de l'âme. In CEuvres et lettres. La Pléiade, Paris: Gallimard.

de Sousa Melo, C. 2002. Possible directions of fit between mind, language and the world. In Essays in speech act theory, ed. D. Vanderveken, and S. Kubo. Amsterdam: Benjamins.

Frege, G. 1977. "Thoughts", "negation" and "compound thoughts. In Logical investigations. New Haven, CT: Yale University Press.

Goldman, A.I. 1970. A theory of human action. Princeton, NJ: Princeton University Press.

Hintikka, J. 1971. Semantics for propositional attitudes. In Reference and modality, ed. L. Linsky. Oxford: Oxford University Press.

Prior, A.N. 1967. Past, present and future. Oxford: Clarendon Press.

Searle, J.R. 1982. Intentionality. Cambridge: Cambridge University Press.

Searle, J.R. 2005. Desire, deliberation and action. In D. Vanderveken (2005c), 49-78.

Searle, J.R., and D. Vanderveken. 1985. Foundations of illocutionary logic. Cambridge: Cambridge University Press.

Vanderveken, D. 1990. Meaning and speech acts, vol. 1. Cambridge: Cambridge University Press. Vanderveken, D. 1991. Meaning and speech acts, vol. 2. Cambridge: Cambridge University Press. Vanderveken, D. 2005a. Propositional identity, truth according to predication and strong implication. In D. Vanderveken (2005c), 185-216.

Vanderveken, D. 2005b. Attempt, success and action generation: a logical study of intentional action. In D. Vanderveken (2005c), 316-342.

Vanderveken, D. (ed.). 2005c. Logic, thought and action. Dordrecht: Springer.

Vanderveken, D. 2008a. Attitudes, tentatives et actions. In Actions, Rationalité \& Décision, ed. D. Vanderveken, and D. Fisette, 39-73. London: College Publications.

Vanderveken, D. 2008b. A general logic of propositional attitudes. In Dialogues, logics and other strange things, Volume 7 of series tributes, ed. C. Dégrémont, et al., 449-483. London: College Publications.

Vanderveken, D. 2009a. Aspects cognitifs en logique intensionnelle et théorie de la vérité. Dialogue 48(1): 103-128. 
Vanderveken, D. 2009b. Beliefs, desires and minimal rationality. In Logic, ethics and all that Jazz. Essays in Honour of Jordan Howard Sobel of Uppsala Philosophical Studies, ed. Johansson, Österberg and Sliwinski, vol. 57, 357-372. Uppsala: Uppsala University.

Vanderveken, D. 2011. Formal semantics for propositional attitudes. Special issue. Science, Truth and Consistency of Manuscrito 24(1): 323-364.

Vanderveken, D. 2012. On the imperfect but minimal rationality of Human Agents. In Rationality and its limits, ed. A. Guseynov, and V. Lektorsky, 136-159. Russian Institute of Philosophy Print: Proceedings of the Meeting in Moscow of the International Institute of Philosophy, Moscow.

Vanderveken, D. 2013. Towards a formal pragmatics of discourse. International Review of Pragmatics 5(1): 34-69. 